\title{
Epigenetic regulation of neurogenesis in the adult hippocampus
}

\author{
M Covic, E Karaca and DC Lie \\ Institute of Developmental Genetics, Helmholtz Center Munich, German Center for Environmental Health, Neuherberg, Germany
}

The dentate gyrus of the hippocampus is an exception to a 'neurogenesis-unfriendly' environment of the adult brain. New functional neurons generated in this region contribute to learning and mood regulation, and thus represent a unique form of neural plasticity. The rate of hippocampal neurogenesis significantly changes on physiological or pathological influences, such as physical activity, environmental enrichment, stress, and aging. We suggest that epigenetic mechanisms could be sensors of environmental changes and fine modulators of adult hippocampal neurogenesis. Here, we examine the role of DNA methylation and methylation of core histones mediated by the Polycomb and Trithorax complexes in the regulation of adult neurogenesis. Given the recent surprising discovery of dynamic and reversible DNA methylation in the hippocampus, we speculate regarding its regulation and its role in adult neurogenesis.

Heredity (2010) 105, 122-134; doi:10.1038/hdy.2010.27; published online 24 March 2010

Keywords: adult neurogenesis; dynamic methylation; histone methylation; DNA methylation; epigenetic modifications; hippocampus

\section{Introduction}

'Chromatin can't be important otherwise bacteria would have it.'

A comment made a few years ago at a transcription meeting (Ordway and Curran, 2002).

If only genomes were important, humans would not have developed more than mice, and plants would have had the same chance of ruling the world (as human, mouse, and Arabidopsis genome share the same number of genes, approximately 25000). In fact, it is the epigenome that has tremendously evolved since the appearance of the first multicellular organisms. The epigenome consists of non-coding RNA and chromatin, a proteinaceous matrix surrounding DNA. The dynamic interactions of post-translationally modified chromatin proteins, covalently modified cytosines inside DNA (also known as the fifth and sixth bases) and non-coding RNA define the complex pattern of gene expression beyond the four bases of DNA (Jenuwein and Allis, 2001; Bird, 2002; Bergmann and Lane, 2003).

The terms epigenetics, that is, interplay between genes and environment resulting in phenotype, and epigenetic landscape, that is, the differentiation potential of any cell, were coined by the developmental biologist Conrad Waddington (Waddington, 1940). Methylation of DNA was the first proposed molecular mechanism behind Waddington's hypothesis (Holliday and Pugh, 1975). Indeed, DNA methylation was later linked to heritable

Correspondence: $\operatorname{Dr}$ M Covic, Institute of Developmental Genetics, Helmholtz Center Munich, Ingolstaedter Landstr.1, Munich 86754, Germany.

E-mail:covicmarcela@yahoo.ca

Received 15 October 2009; revised 9 February 2010; accepted 11

February 2010; published online 24 March 2010 inactivation of $\mathrm{X}$ chromosomes and genomic imprinting (Wolffe and Matzke, 1999). The understanding of DNA methylation as a long-lasting cellular memory necessary to maintain a cellular phenotype has recently been challenged by discoveries of its dynamic nature (Miller and Sweatt, 2007; Kangaspeska et al., 2008; Metivier et al., 2008). DNA methylation is now also seen as a dynamic epigenetic change, such as histone acetylation and methylation (Bird, 2007).

Simple organisms, such as bacteria, increase their rate of spontaneous mutations to enable the survival of species in a changing environment. Multicellular organisms use complex mechanisms coordinated by the central nervous system to behaviorally adapt to changing environments without paying the high price of mutating their genome (Colvis et al., 2005). Their behavioral adaptation depends on learning and long-term changes in synaptic connectivity (Kandel, 1984), often mediated or supported by epigenetic mechanisms (Fischer et al., 2007; Guan et al., 2009; Roth and Sweatt, 2009; Sweatt, 2009). Given the essential role of the hippocampus in learning and memory, it is not too surprising that the first evidence of dynamic DNA methylation in the adult central nervous system was found here (Miller and Sweatt, 2007). The hippocampus is also one of the two regions in which a specialized form of neural plasticity, that is, the generation of new functional neurons from neural stem cells, occurs throughout adult life. This process, which is also termed adult hippocampal neurogenesis, contributes to learning and memory formation and the regulation of mood (Drapeau et al., 2003; Zhao et al., 2008).

This review focuses on the emerging appreciation of dynamic epigenetic mechanisms regulating adult hippocampal neurogenesis. First, we examine the epigenetic 
modifications involved in the control of neurogenesis in the adult hippocampus. For clarity, regulators of adult hippocampal neurogenesis will be divided into intrinsic factors, that is, transcription factors (TFs) that are synthesized by the developing neural precursors and neurons, and extrinsic factors, that is, growth factors and neurotrophins secreted from the surrounding niche. The emphasis will be put on DNA methylation and histone methylation through the Polycomb (PcG) and Trithorax (TrxG) complexes. For other epigenetic mechanisms, including ATP-dependent chromatin remodeling, histone de/acetylation, neuron-restrictive silencing factor (NRSF/REST)-mediated gene regulation and non-coding RNA, we refer the reader to excellent reviews (Ballas et al., 2005; Hsieh and Gage, 2005; Hamby et al., 2008; Hsieh and Eisch, 2010). Secondly, we analyze the evidence suggesting that DNA methylation may transmit the environmental influence on the regulation of adult neurogenesis. Finally, we speculate about one of the hottest questions in epigenetics today: what might be the role of dynamic DNA methylation in neurogenesis and how might it be regulated?

\section{Epigenetic control of intrinsic factors of adult hippocampal neurogenesis}

The development of hippocampal dentate granule neurons from neural stem cells is regulated by a series of cell-autonomous or intrinsic gene expression programs that are controlled by TFs; (see, Figure 1 for the description of stages of neuronal development in the adult hippocampus). Neural stem cells are located in the subgranular zone of the dentate gyrus. These cells are slowly dividing and display a radial glia-like morphology. It has been suggested that these radial glia-like stem cells (type 1 cells) give rise to highly proliferative, non-radial neural stem cells (type 2 cells), which will be referred to here as neural progenitor cells (NPCs). Type 2 cells commit to a neuronal fate and differentiate into immature neurons that will subsequently mature into functional granule neurons and integrate into the existing hippocampal neural network.

Although the identity of the primary neural stem cell in the hippocampus and the lineage relationship between type 1 and type 2 cells is currently controversial (Tropepe, 2007), there is a consensus that the undifferentiated state and self-renewal of adult NPCs is controlled by the high-mobility-group DNA-binding protein Sox2 (Suh et al., 2007). The neuronal lineage commitment of NPCs, their exit from the cell cycle and further neuronal maturation is initiated by TFs of the basic helix-loop-helix (bHLH) family: Ngn2, NeuroD1 and NeuroD2 (Pleasure et al., 2000; Ozen et al., 2007; Gao et al., 2009; Kuwabara et al., 2009; Roybon et al., 2009). The TFs of the SoxC family, Sox4 and Sox11, also seem to be transiently expressed during early stages of neuronal fate commitment (Figure 1), but their role in adult neurogenesis is presently unknown (Bergsland et al., 2006; Haslinger et al., 2009).
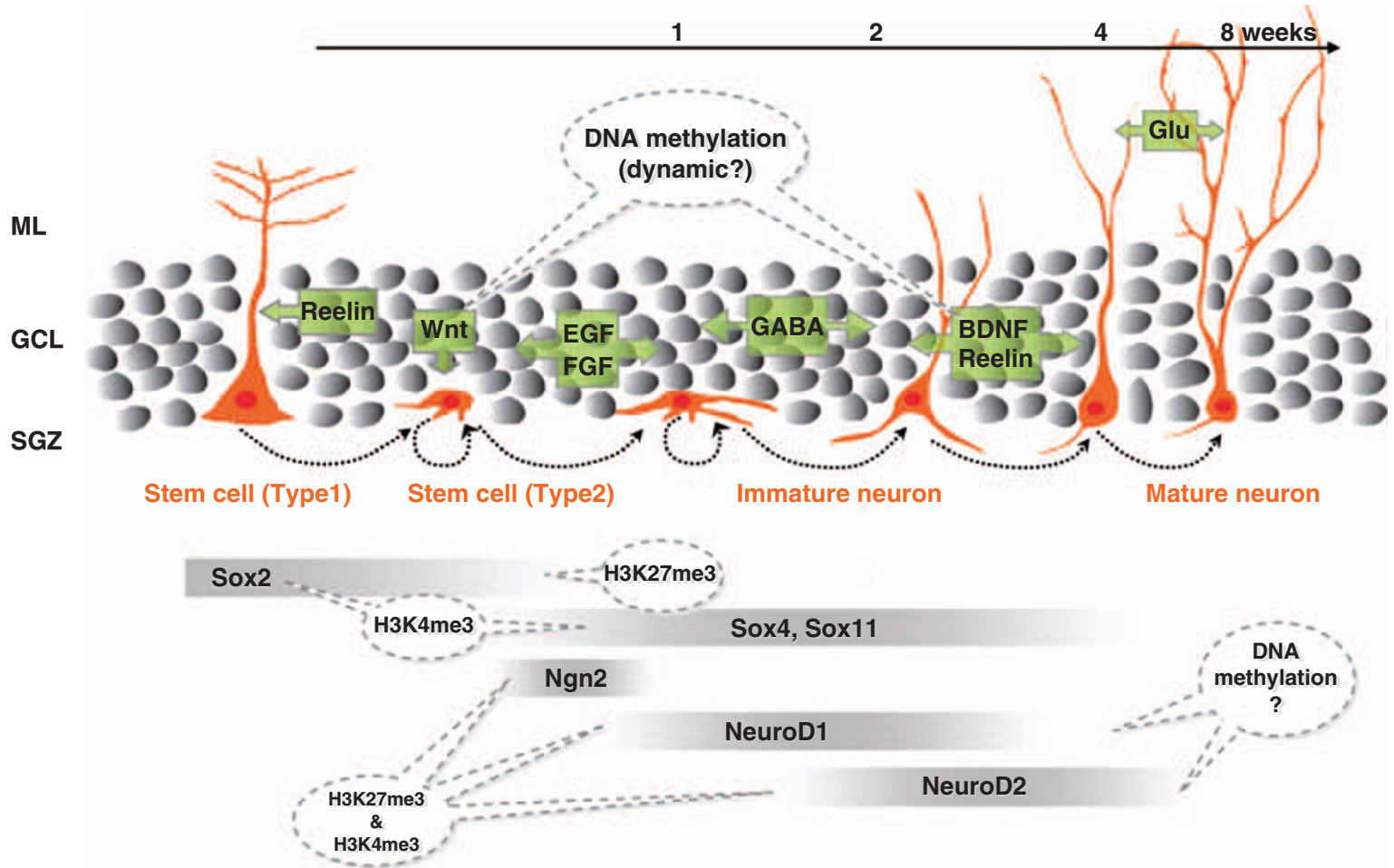

Figure 1 Dentate gyrus of the adult hippocampus continuously generates neurons. Type 1 cell represents a rarely dividing radial glia-like stem cell and Type 2 cell represents a rapidly and transiently proliferating stem/progenitor cell. These cells are situated in the subgranular zone (SGZ) of the dentate gyrus. Type 2 cells will become neuronally committed and further develop into a mature neuron that will integrate into the granular zone (GZ) of the dentate gyrus. Radial glia-like cells and neurons project their dendrites into the molecular layer (ML). Extrinsic factors that influence adult neurogenesis are shown in green boxes. Intrinsic factors involved in hippocampal neurogenesis and their temporal expression are depicted in grey rectangles. The epigenetic mechanisms that may regulate extrinsic and intrinsic factors are shown in bubbles. BDNF, brain-derived neurotrophic factor; EGF, epidermal growth factor; FGF, fibroblast growth factor; GABA, $\gamma$-amino- $n$-butyric acid A; GCL, granule cell layer; Glu, glutamate; ML, molecular layer; SGZ, subgranular zone. 
Role of DNA methylation is still unclear

One of the earliest proposed roles for DNA methylation was the restriction of developmental potentials and prevention of de-differentiation of terminally differentiated cells (Hochedlinger and Plath, 2009). Its role in cellular differentiation was disputed (Walsh and Bestor, 1999) and the current model is that, at least, repression of inactive $X$ chromosomes and imprinted genes (silencing of parasitic sequence elements is still questionable) depends on heritable DNA methylation (Suzuki and Bird, 2008). In differentiated mammalian cells, DNA methylation seems restricted to CG dinucleotides; however, some studies have also detected non-CG methylation (Woodcock et al., 1987; Inoue and Oishi, 2005; Metivier et al., 2008). The CG methylation is thought to alter chromatin density and DNA accessibility by blocking the binding of TFs to their cognate DNA sequences and/or increasing the recruitment of the methyl-binding proteins and histone deacetylases (Bird, 2002). In addition to high levels of CG methylation, embryonic stem cells also exhibit abundant non-CG methylation in $\mathrm{mCHG}$ and $\mathrm{mCHH}$ contexts where $\mathrm{H}=\mathrm{A}, \mathrm{C}$ or $\mathrm{T}$ (Ramsahoye et al., 2000; Lister et al., 2009). Non-CG methylation might have an important role in the maintenance of pluripotency, as it re-appears in induced pluripotent cells and is abundant in gene bodies of highly expressed genes (Lister et al., 2009). Both non-CG methylation and some CG methylation seem to be enriched on transcribed strands, yet, the relevance of such asymmetric methylation is currently unknown (Inoue and Oishi, 2005; Metivier et al., 2008; Lister et al., 2009). Methylation of DNA is catalyzed by DNA methyltransferases (DNMTs). The DNMT1 protein faithfully maintains the pattern of methylated CGs that would otherwise become lost through cell divisions, whereas the de novo methyltransferases, DNMT3a/b, can also catalyze non-CG methylation (Suetake et al., 2003; Metivier et al., 2008; Lister et al., 2009). The expression levels of DNMTs usually decrease as cells differentiate; however, DNMT1 and DNMT3a remain expressed even in the largely post-mitotic adult brain, including the hippocampus (Feng et al., 2005).

As no systematic analysis of DNA methylation during neuronal development in vivo has been performed yet, it is still unclear whether adult hippocampal neurogenesis uses DNA methylation for repression of multipotency genes, such as Sox2, and/or transient-fate determinants, such as the bHLH and SoxC family members. Here, we will present the evidence from genome-wide methylation profiling of 15,100 validated promoters during in vitro neuronal differentiation of embryonic stem cells (ESCs; Mohn et al., 2008). The loss of methylation was observed in $0.1 \%$ of analyzed promoters and was largely restricted to the brain-specific genes. The gain of methylation was 20 times more frequent and it occurred on promoters of germline-specific and pluripotency genes, including Nanog and Oct4. In addition to Nanog and Oct4, Sox2 is an essential component of transcriptional networks controlling pluripotency of ESCs (Masui et al., 2007) and multipotency of hippocampal NPCs (Suh et al., 2007). Surprisingly, the Sox2 proximal promoter stays methylation-free in differentiated ESCderived glutamatergic neurons and in adult brain tissue (Meissner et al., 2008; Mohn et al., 2008). However, the Sox2 upstream enhancer SRR1 was found to be methylated in astrocytes and neurons derived from the embryonic carcinoma NT2-D1 cells (Sikorska et al., 2008). In this model system, Sox 2 enhancer methylation in astrocytes seemed to be reversible, as the addition of growth factors caused its transient demethylation and Sox 2 messenger RNA (mRNA) upregulation. This intriguing finding of reversible Sox 2 methylation adds to the recent evidence showing the dynamic face of DNA methylation (Metivier et al., 2008; Ma et al., 2009b). Nevertheless, as the prolonged passaging or differentiation of cultures in vitro yields abnormal accumulation of DNA methylation and this often occurs on genes that are usually never methylated (Shen et al., 2006; Allegrucci et al., 2007; Meissner et al., 2008), the aforementioned observation of dynamic Sox2 enhancer methylation awaits to be confirmed in vivo.

Similarly to Sox2, the promoter methylation of transient fate determinants of the bHLH and SoxC families was also not detected neither in stem nor in differentiated cells (Fouse et al., 2008; Meissner et al., 2008; Mohn et al., 2008). As the promoters of these genes are high CpG island promoters, this might explain their DNA methylation-free status (Weber et al., 2007; Mohn et al., 2008; Suzuki and Bird, 2008). Nevertheless, one should keep in mind that small changes in DNA methylation (situated on only one or a few not densely packed CGs) might not be detected by genome-wide DNA methylation profiling methods, such as the methyl-cytosine immunoprecipitation and reduced-representation bisulfite sequencing used in the above-mentioned studies (Fouse et al., 2008; Meissner et al., 2008; Mohn et al., 2008). Here we will provide one example. The above genome-wide studies did not detect any profound methylation of NeuroD1 and NeuroD2 in ESC-derived glutamatergic neurons, the brain tissue and various non-neural differentiated cells (Meissner et al., 2008; Mohn et al., 2008). However, using a highly sensitive MethyLight method (Eads et al., 2000), the age-dependent increase in the methylation of NeuroD1 and NeuroD2 promoters was detected in the cortex (Siegmund et al., 2007). The accumulated methylation occurred on CGs overlapping with the Egr1/NGFIA/Zif268/Krox-24-binding sequence that is positioned close to the putative binding sites of Neurogenins (Ngn), neuronal determination factors that directly stimulate expression of NeuroD1 (Bertrand et al., 2002). Interestingly, adverse early-life conditions, such as motheroffspring neglect and childhood abuse were found to increase the methylation of Egr-1-binding sequences causing lower expression of Egr1 target genes later in adult life (Weaver et al., 2007; McGowan et al., 2009). As adult neurogenesis is negatively correlated with stress and depression (Zhao et al., 2008) and major depression correlates with increased DNA methylation in the cortex (Veldic et al., 2005), this raises an intriguing possibility: could the depression-linked decrease in adult neurogenesis be a consequence of the increased methylation of NeuroD1 promoter in developing neurons?

Taken together, DNA methylome profiling of ESCderived neurogenesis in vitro showed that the majority of de novo promoter methylation changes occur between the transition from pluripotent cells (ESCs) to lineagerestricted progenitor state (NPCs) and, most surprisingly, not during their further transition into terminally differentiated neurons (Meissner et al., 2008; Mohn et al., 2008). If we extend this observation to adult 
neurogenesis, promoter hypermethylation might not be responsible for the final repression of intrinsic fate-determination TFs, which occurs in later stages of neuronal development (Figure 1). Nevertheless, one should keep in mind that the subtle changes of DNA methylation on individual CG sites during neuronal maturation might have escaped detection in these studies.

Dynamic control by PcG and TrxG group

Members of the PcG complex catalyze trimethylation of lysine 27 of histone 3 (H3K27me3), which leads to transcriptional repression through local heterochromatin formation (for review, see Cedar and Bergman (2009)) and/or inhibition of transcriptional elongation through stalling of RNA polymerase II (Stock et al., 2007). It remains elusive how PcG complexes are recruited to chromatin in mammals (Hublitz et al., 2009). TrxG complex is recruited by RNA polymerase II and catalyzes H3K4 trimethylation (H3K4me3) of promoterproximal nucleosomes (Hughes et al., 2004). However, the presence of $\mathrm{H} 3 \mathrm{~K} 4 \mathrm{me} 3$ does not predict efficient gene expression as the majority of inactive genes experience transcription initiation (Guenther et al., 2007). H3K27me3 and $\mathrm{H} 3 \mathrm{~K} 4 \mathrm{me} 3$ can co-occupy the same promoters and such 'bivalent chromatin structure' is thought to allow fast activation of gene expression (Bernstein et al., 2006; Zhao et al., 2007b). Typically, Polycomb-induced repression is easy to reverse and dynamic gain and loss of Polycomb- and Trithorax-mediated histone modifications occur during in vitro developmental progression from ESCs to fully differentiated neurons (Mohn et al., 2008; Nottke et al., 2009).

The PcG-mediated repression of the Sox2 promoter occurs during differentiation of NPCs (Mohn et al., 2008) and in differentiated cells, such as murine embryonic fibroblasts (Mikkelsen et al., 2007). How PcG complexes get recruited to the Sox2 promoter during neuronal differentiation is not known. Unlike the pluripotency and multipotency factor Sox2, developmental TFs, such as Ngn2, NeuroD1, NeuroD2, Sox4, and Sox11 are repressed by a PcG-mediated mechanism already in pluripotent ESCs. They all have bivalent promoters (that is, both $\mathrm{H} 3 \mathrm{~K} 27 \mathrm{me} 3$ and $\mathrm{H} 3 \mathrm{~K} 4 \mathrm{me} 3$ ) suggesting that they are poised to be activated (Mikkelsen et al., 2007; Fouse et al., 2008; Mohn et al., 2008). In multipotent NPCs, Ngn1, Ngn2, and NeuroD2 retain the 'closed' (H3K27me3) promoter conformation, whereas promoters of Sox4 and Sox11 become 'open' (no H3K27me3; Mikkelsen et al., 2007; Mohn et al., 2008). Such a promoter conformation might allow the SoxC family members to become transcribed before the bHLH-family members, yet whether this would also occur in uncommitted type II cells during hippocampal neurogenesis remains elusive. The role of the SoxC family in neuronal development is not fully understood and it was suggested that SoxC proteins control the establishment of pan-neuronal gene expression (Bergsland et al., 2006) in contrast to proneural bHLH proteins that have been linked to the control of neuronal subtype identity (Berninger et al., 2007). However, Sox4 and Sox11 might also have other functions as they are expressed during other adult differentiation programs, such as in oligodendrocytes, lymphocytes, pancreatic beta cells and osteoblasts (Kuhlbrodt et al., 1998; Potzner et al., 2007; Penzo-Mendez, 2010), in many malignancies and behave as oncogenes (Ikushima et al., 2009; Scharer et al., 2009). Taken together, proneural bHLH and SoxC TFs-while both are involved in neuronal fate determination and differentiation-seem to be regulated by a distinct temporal pattern of PcG-mediated repression. Whether such differential temporal control is causally linked to their differential function in neuronal fate determination and differentiation remains to be clarified.

Given the repression of the proneurogenic bHLH by $\mathrm{H} 3 \mathrm{~K} 27 \mathrm{me}$, it is plausible that histone demethylases could be involved in neuronal fate determination through removal of the $\mathrm{H} 3 \mathrm{~K} 27 \mathrm{me} 3$ marks and activation of pro-neurogenic bHLH factors. Jmjd3/Kdm6b, a member of the Jumonji C family of histone demethylases, stimulates neurogenesis in the embryonic central nervous system and in neural commitment in vitro (Jepsen et al., 2007; Burgold et al., 2008). Which factors might recruit histone demethylases to their proneural TF targets is still a mystery. This brings us to the next speculation: could the presence of Jmjd3 or the ability to recruit it to the pro-neurogenic TFs be a molecular determinant of neurogenic activity in the adult brain? Except for the two specialized neurogenic areas, the dentate gyrus of the hippocampus and the subventricular zone of the lateral ventricle, neural stem cells in the adult brain generally give rise to glia. Interestingly, NPCs transplanted from the gliogenic (for example, the spinal cord or the substantia nigra) to neurogenic areas of the adult brain (dentate gyrus of the hippocampus) start to differentiate into neurons rather than into glia (Shihabuddin et al., 2000; Lie et al., 2002). This indicates that the extrinsic signals from the local environment can redirect the fate of transplanted NPCs. Does such fate switch involve the activation or the proper recruitment of the endogenous H3K27me3 demethylases? Finding the proper chemical compounds that could activate the expression of appropriate histone demethylases and thus stimulate neuronal determination programs would be of tremendous significance for efficient neuronal regeneration after injuries in non-neurogenic regions of the adult brain.

\section{The importance of being CG-rich and the curious case of Sox2}

Transcription factors involved in adult neurogenesis are single-exon genes, for example, Sox2, Sox4, and Sox11, or two-exon genes, for example, Ngn2, NeuroD1, and NeuroD2, that are embedded in long stretches of high CG densities (CpG islands). The sizes of their CpG islands range between $1200-2500$ bps with the exception of a shorter CpG island in NeuroD1. Such a genomic organization might offer several advantages. First, the intron-poor structure might allow their fast rate of transcription and a rapid adaptation to a changing environment (Jeffares et al., 2008), which might be one of the potent mechanisms modulating the rate of adult neurogenesis. Second, as CG-rich genes are preferentially regulated at the transcriptional elongation stage, this might give them a selective advantage of becoming rapidly upregulated on appropriate stimuli (Hargreaves et al., 2009; Ramirez-Carrozzi et al., 2009). Third, pluripotency TFs in various stem/progenitor cells 
fluctuate in their transcription (Chambers et al., 2007; Chang et al., 2008; Hayashi et al., 2008). Whether the fast and fluctuating expression might be linked and caused by their CG-rich promoters is not known, however, it has been speculated that stochastic fluctuations allow the fast switching in cell-fate decisions in undifferentiated cells (Mohn and Schubeler, 2009). Do similar phenomena hold true for anti-differentiation (Sox2) and neurogenic determination (Ngn2, NeuroD) factors in adult hippocampal NPCs? So far, there has been no study analyzing this question, however, there is intriguing evidence that both classes might show fluctuating gene expression. For example, Ngn2 protein already appears days before the onset of the neuronal differentiation of early embryonic NPCs. As Ngn2 expression follows an oscillatory pattern, it was proposed that this would yield Ngn2 protein levels that are too low and insufficient to stimulate neuronal differentiation (Shimojo et al., 2008). Whether such a low level of Ngn2 in early NPCs is caused by its CG-rich structure-mediated leaky and inefficient transcription is not known. Genome-wide chromatin immunoprecipitation profiling of Sox2 downstream targets in ESCs surprisingly showed that one-half of all Sox2/Oct/Nanog-bound genes represent CG-rich developmental TFs (Kim et al., 2008). These included pro-neurogenic TFs (Ngn1 and Ngn2), pro-gliogenic TFs (Olig 3), and many other developmental TFs (Dlx1, Dlx5, Pitx2, HoxC, Pax3 and so on). Knowing that Sox2 is essential for keeping cells undifferentiated, why would it interact with the promoters of developmental TFs at all? This evidence (contradictory at first glance) was explained by the repressive activity of Sox2 (Bylund et al., 2003; Kim et al., 2008; Kuwabara et al., 2009). Similarly, in vitro evidence showed that lower levels of Sox2 activate the transcription of pluripotency genes, whereas higher levels of Sox2 repress it (Boer et al., 2007). Nevertheless, in vitro data should be analyzed with caution, as overloading artificially high levels of TFs may create effects that do not exist in vivo. As the pluripotency genes, such as Nanog, also show fluctuating expression in ESCs (Chambers et al., 2007), could this imply that the transcription of the Sox 2 gene also fluctuates and causes oscillatory expression of developmental TFs without leading to differentiation? Whether the latter would occur through the increased elongation efficiency of appropriate developmental TFs triggered by a certain differentiation cue remains to be verified.

Overall, intron-poor and CG-rich structure might be an advantage for the intrinsic TFs of adult neurogenesis. It might allow their fast transcriptional activation by environment-mediated differentiation cues without the need for chromatin remodeling. It will be interesting to determine whether the NPCs of the adult brain also use fluctuating gene expression and how this relates to their decision to generate neurons or astrocytes.

\section{Epigenetic control of extrinsic factors of adult hippocampal neurogenesis}

The rate of hippocampal neurogenesis is not static but is dynamically regulated by environmental influences and complex behavior. Stress and aging are among the most potent negative regulators of hippocampal neurogenesis. In contrast, exposure to an enriched environment, physical activity, and learning increase the generation of new neurons, which lead to the hypothesis that the rate of neurogenesis is constantly adapting to the needs of the hippocampal circuitry (Zhao et al., 2008). Extrinsic factors, such as growth factors and neurotransmitters, secreted by the stem cell niche, diffusing from the nearby vasculature or released from synaptic connections relay the environmental influence onto the progression of neurogenesis in the adult hippocampus (see Figure 1). As there has been less evidence about their regulation by histone methylation, we will present the evidence about their DNA methylation.

Fgf signaling: In a recent study, fibroblast growth factor 1 (Fgf-1) was found to be one of the environmental signals promoting adult hippocampal neurogenesis (Ma et al., 2009b). Hippocampal network activity in the physiological context and in the context of epilepsy and of anti-depressive electro-convulsive treatment is a potent stimulator of adult hippocampal neurogenesis. Ma et al. used electro-convulsive treatment to examine genomewide changes in DNA methylation that correlate with increased adult hippocampal neurogenesis. Astonishingly, electro-convulsive treatment induced a transient decrease in methylation of the Fgf-1 brainspecific promoter in mature dentate granule neurons. Methylation levels of the $F g f-1$ promoter returned to initial levels a few hours later and correlated with a transient increase in Fgf-1 mRNA expression. This breakthrough study provided the first evidence that stimulation of adult neurogenesis might be regulated through transient DNA demethylation of extrinsic factors in the hippocampal neurogenic niche.

Other members of the Fgf family and a receptor of Fgf ligands see to be also regulated by DNA methylation. A genome-wide DNA methylation profiling study showed that Fgf16, Fgf17, Fgf20 and Fgfr4 are highly methylated in cultured astrocytes (Meissner et al., 2008). Given the essential role of astrocytes in the hippocampal neurogenic niche in the control of neurogenesis (Song et al., 2002), it is tempting to speculate that dynamic promoter methylation might regulate expression of these Fgfs and contribute to the regulation of adult hippocampal neurogenesis.

Wnt signaling: Astrocytes in the adult dentate gyrus stimulate neurogenesis through secretion of Wnt molecules (Lie et al., 2005). Intriguingly, the promoters of Wnt3, Wnt10b, and Wnt2 were highly methylated in ESC-derived astrocytes (Meissner et al., 2008). This was surprising because the promoters of Wnt genes contain strong $\mathrm{CpG}$ islands that usually stay methylation-free (Bird, 2002). As the extent of their methylation was much lower in the brain and in lower passage astrocytes, the authors concluded that their high methylation may just be an in vitro artifact of the prolonged passaging of cells (Meissner et al., 2008), a phenomenon that was previously observed (Shen et al., 2006; Allegrucci et al., 2007). It will be interesting to determine whether aging increases DNA methylation of astrocyte-secreted Wnt factors, which might explain the lower rate of neurogenesis in old brain (Zhao et al., 2008) and the observation that early postnatal astrocytes are more efficient in promoting the in vitro neuronal differentiation of NPCs than astrocytes derived from the adult brain (Song et al., 2002). 
GABA signaling: Increased hippocampal activity correlates with the increased release of the neurotransmitter $\gamma$-amino- $n$-butyric acid A (GABA). Increased GABAergic signaling promotes the proliferation of NPCs and their neuronal fate determination through induction of NeuroD1 (Deisseroth et al., 2004; Tozuka et al., 2005). Examination of cortical tissue of aged subjects and of patients who suffered from neuropsychiatric disorders suggested that DNA methylation might regulate the expression of the enzymes and receptors involved in GABA signaling. For example, GABA-synthesizing glutamic acid decarboxylase 65 (GAD65/GAD1) and GABA receptor alpha 2 (GABRA2) showed age-dependent increase in their DNA methylation (Siegmund et al., 2007), whereas GABA receptor alpha 1 (GABRA1; Poulter et al., 2008) and glutamic acid decarboxylase 67 (GAD67/GAD2) were methylated more in suicide/major depressive disorder victims and in schizophrenic and psychotic patients, respectively (Veldic et al., 2005). In all cases, increased DNA methylation was inversely correlated with mRNA levels. There has been, so far, no direct evidence that DNA methylation (or any other epigenetic mechanism) could regulate the GABA signaling-stimulated hippocampal neurogenesis.

\section{Reelin}

Reelin is an extracellular matrix protein that is implicated in embryonic and adult neurogenesis. Migration of immature neurons is coordinated by Reelin and in its absence, the development, and maintenance of the radial glia-like stem cells (type 1 cells) is impaired (Zhao et al., 2007a; Sibbe et al., 2009). The first indication of Reelin regulation by DNA methylation comes from the studies on patients with schizophrenia and psychotic bipolar disorder, in which lower mRNA levels of Reelin correlated with its promoter hypermethylation (Veldic et al., 2005).

The first firm proof of dynamic DNA methylation in the adult brain came from a seminal study by Miller and Sweatt (2007), who investigated DNA methylation in the CA1 region of the hippocampus (see Figure 2) and its role in memory consolidation. In the context of fearconditioning training, rapid demethylation of Reelin already occurred within $1 \mathrm{~h}$ and this demethylation event was essential for the transcriptional activation of Reelin and memory formation. Methylation of the Reelin gene returned to initial levels several hours after fear-conditioning training-a surprising piece of evidence that DNA methylation in post-mitotic cells can be dynamic and reversible (Miller and Sweatt, 2007).

\section{Brain-derived neurotrophic factor}

Brain-derived neurotrophic factor (BDNF) is a neurotrophin that promotes the proliferation of neural precursors and the maturation and integration of newly generated neurons in adult hippocampal neurogenesis (Bergami et al., 2008; $\mathrm{Li}$ and Keifer, 2009). It is normally synthesized in mature neurons in the granular cell layer of the dentate gyrus at much higher concentration than in other neurons of the brain and is localized in their axons (Scharfman, 2004). In vitro depolarization increased transcription of $B d n f$, which correlated with a decrease in methylation of some of its promoter CGs
Epigenetics in adult neurogenesis

$\mathrm{M}$ Covic et al

(Chen et al., 2003; Martinowich et al., 2003). In addition, DNA demethylation of the distinct Bdnf promoters occurred during memory consolidation and neurogenesis in adult hippocampus (see, Figure 2; Lubin et al., 2008; Ma et al., 2009b).

\section{Dynamic DNA methylation: necessary for environmental} regulation of adult neurogenesis?

The rate of neurogenesis in adult hippocampus is regulated at several stages: (i) proliferation of neural progenitors (ii) survival of newborn neurons and (iii) maturation and integration of newly generated neurons (Figure 1). Several thousands of neurons are produced each day in the hippocampus of adult rodents, yet only a fraction of them finally survive (Kempermann et al., 2003). The low survival of adult-born neurons might be a consequence of a selection for neurons that are best fitted to the actual environmental demands; however, the responsible molecular mechanisms are not clear. Here, we examine the hypothesis that dynamic DNA methylation, recently discovered to be essential for hippocampal-dependent learning and memory formation, could transmit the physiological and pathological influences onto adult neurogenesis.

Environmental influences are strong modulators of adult hippocampal neurogenesis. The proliferation of NPCs is enhanced by anti-depressive treatments, seizures, and physical activity, whereas their fate determination and maturation are strongly impaired in aging and stress (Zhao et al., 2008). Interestingly, physical activity counteracts some adverse effects of aging on neuronal maturation (van Praag et al., 2005). Aging seems to decrease the neurogenic character of the hippocampal stem cell niche because stem cells in the aged dentate gyrus show decreased proliferation and generate less neurons but more astrocytes (van Praag et al., 2005). Voluntary running of old animals augments the number of their newborn neurons to the same extent as running of young animals. Voluntary exercise induces the expression of BDNF and Fgf2 in the adult brain (Cotman and Berchtold, 2002) and these and other neurotrophins and growth factors have been recently found to be regulated by dynamic and reversible DNA methylation (Veldic et al., 2005; Miller and Sweatt, 2007; Lubin et al., 2008; Ma et al., 2009b). Running also increases the expression of Egr1/NGFI-A/Zif268/Krox-24, an immediate early gene (Tong et al., 2001). What role it has in adult neurogenesis, that is, whether it can stimulate the expression of intrinsic factors, such as NeuroD in NPCs/developing neurons, remains elusive.

Despite the running-mediated increase in neurogenesis in old animals, the total number of neurons they generate is still much lower than in non-running young animals. This suggests that some of the mechanisms that repress neurogenesis in old brain might stay irreversible. As an accumulation of DNA methylation of intrinsic factors, such as Sox2, NeuroD1 and NeuroD2, has been detected in cultured astrocytes and in the aged cortex (Siegmund et al., 2007; Sikorska et al., 2008), we raise the following questions: (i) does the observed methylation of Sox 2 in astrocytes also occur in aged stem cells and would it decrease their ability to differentiate and give rise to new neurons? (ii) Does the age-correlated increase in DNA methylation of NeuroD1/2 also occur in aged 


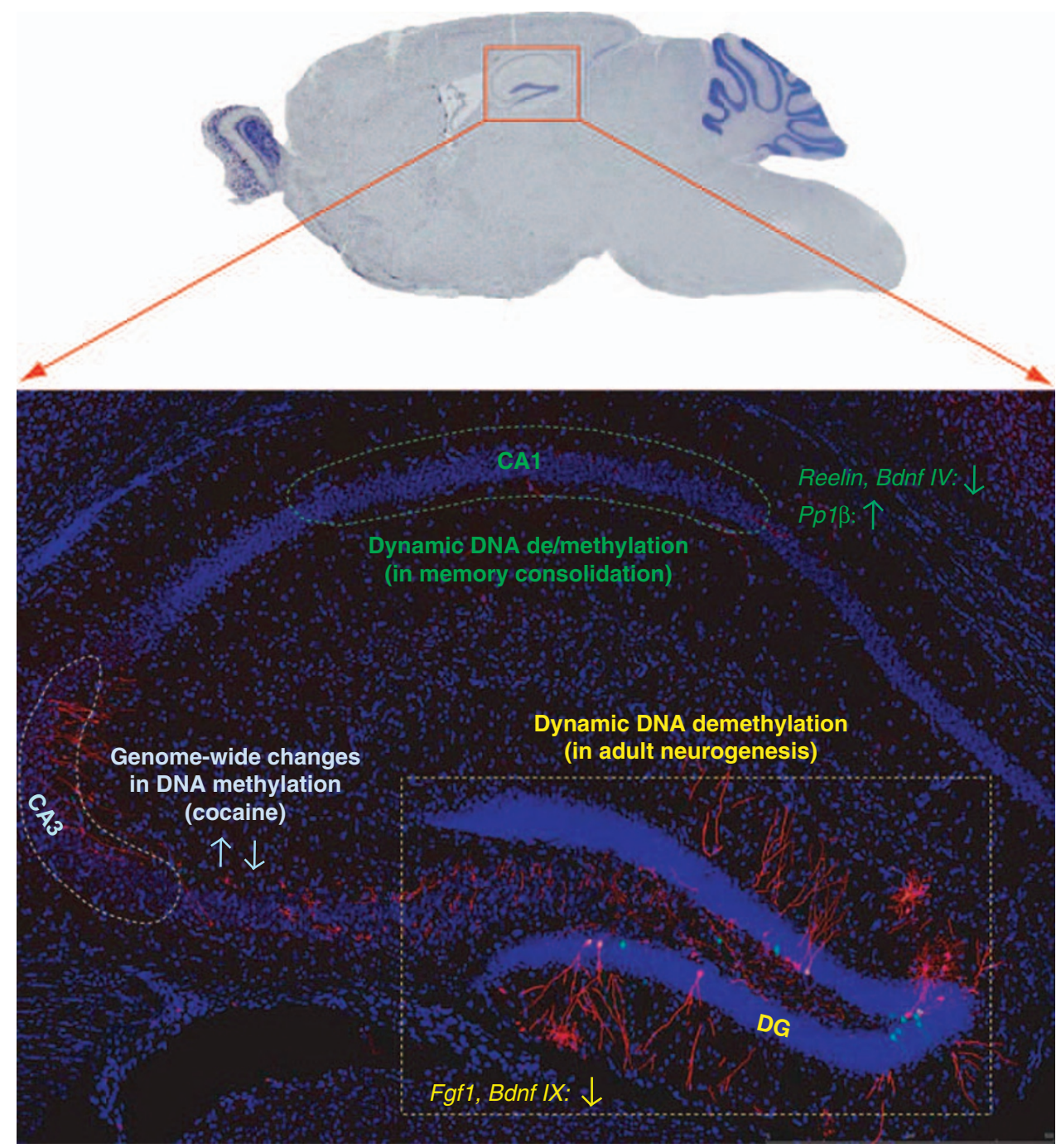

Figure 2 Evidence of dynamic DNA methylation in the adult hippocampus. (i) Granule neurons on the dentate gyrus (DG) show rapid demethylation of $F g f-1$ and $B d n f$ exon IX after electroconvulsive treatment that correlates with an increase in neurogenesis (Ma et al., 2009b); (ii) Pyramidal neurons of the CA1 region show rapid decrease in methylation of Reelin and Bdnf and increase in methylation of Protein phosphatase $1 \beta$ as a part of memory consolidation (Miller and Sweatt, 2007; Lubin et al., 2008); (iii) Pyramidal neurons of the CA3 region in the offspring have perturbed levels of DNA methylation due to maternal cocaine administration during the late stages of gestation (Novikova et al., 2008). Note: Gain or loss of DNA methylation is indicated by arrows. Red and green cells in the DG correspond to the 4-week-old adult-born neurons that were labeled with red/green retroviruses. Blue cells correspond to the 4',6-diamidino-2-phenylindole (DAPI)-stained nuclei representing neurons and glial cells. (Images of the Nissl-stained section of the mouse brain and the fluorescently stained section of hippocampus are courtesy of E Englberger and S Herold.)

NPCs/immature neurons, thus restraining their further maturation through, for example, decreased affinity for the Egr1/NGFI-A/Zif268/Krox-24 TF? (iii) Are the epigenetic mechanisms repressing the extrinsic regulators of neurogenesis easier to reverse than the epigenetic mechanisms controlling the intrinsic regulators of neurogenesis?

Increased synaptic plasticity and lower threshold to induce long term potentiation are characteristic features of newborn neurons in adult hippocampus (Ge et al., 2007). While it has been shown that the expression of T-Type Calcium Channel (Schmidt-Hieber et al., 2004) and the expression of the NMDA Receptor 2B subunit (Ge et al., 2007) are involved in mediating their increased plasticity, it remains unknown which additional factors contribute to their unique neurophysiological properties. Curiously, ongoing dynamic regulation of
DNA de/methylation processes might be necessary for the induction of long term potentiation and plasticity, thus allowing proper learning and memory consolidation. For example, exposure to an enriched environment promotes the maturation of newborn neurons in adult hippocampus (Zhao et al., 2008) and strongly induces Dnmt1 mRNA in the mouse cortex (Rampon et al., 2000). At this stage, it is not known whether the latter also occurs in the adult hippocampus. Addition of zebularine and 5-aza-2-deoxycytidine, inhibitors of DNMT activity, blocks the induction of long-term potentiation in hippocampal slices (Levenson et al., 2006). Similarly, infusion of DNA methylation inhibitors into the CA1 region of the hippocampus disturbs the hippocampal tasks, such as learning and memory consolidation, despite the increased levels of $B d n f$ transcripts (Miller and Sweatt, 2007; Lubin et al., 2008). Despite the concern 
about the specificity of the DNMT inhibitors, dynamic control of DNA de/methylation in adult brain thus seems necessary for plasticity and might regulate the late stages of neuronal maturation.

In conclusion, a common trait of the described complex behavioral conditions and their positive/negative influence on adult neurogenesis is the change of microenvironmental properties in the brain. Dynamic changes in DNA methylation of extrinsic factors seem to have a role in the regulation of neuronal proliferation and survival.

\section{Understanding the dynamics of DNA methylation}

Methylation of DNA of the whole genome is remarkably reset during early embryonic life (for more information, see Figure 3; Reik, 2007). Owing to such global re-establishment of methylation patterns, early pregnancy is thought to be particularly sensitive to adverse environmental influences, such as inadequate nutrition or stress, which have been correlated with increased emergence of anxiety, diabetes, obesity, and cancer in adulthood (Jirtle and Skinner, 2007). In addition, adverse postnatal social environment seems to alter DNA methylation, leading to higher stress responses in adult life (Liu et al., 1997; McGowan et al., 2008, 2009). To summarize, these studies suggested that distinct genes, during certain developmental stages, may be prone to DNA methylation alterations, which, at least in some cases, persist into adult life.

However, a wealth of recent and unexpected evidence pointed out that DNA methylation is also dynamic and reversible. For example, estrogen-induced gene transcription of the $p S 2$ gene showed striking cyclic changes in its promoter DNA methylation (Kangaspeska et al., 2008; Metivier et al., 2008). Maternal cocaine exposure during the second and third trimesters of gestation in mice altered the DNA methylome in the hippocampus of the offspring (Novikova et al., 2008). In this paradigm, some of the abnormally methylated targets disappeared in the postnatal stage, whereas others emerged at the prepubertal stage. This evidence of dynamic changes in global DNA methylation in the postnatal hippocampus goes in line with two recent observations confirming dynamic and reversible DNA methylation in the adult hippocampus (see Figure 2). The study by the Sweatt group (Miller and Sweatt, 2007) discovered that memory consolidation, a typical hippocampal task, depends on active DNA de/methylation, whereas the study by the Song and colleagues (Ma et al., 2009b) provided the first evidence that dynamic DNA methylation would regulate hippocampal neurogenesis.

Which genomic regions could be preferentially regulated by dynamic DNA methylation? Genome-wide mapping suggested that the majority of DNA methylation occurs on promoters with low or intermediate amounts of CGs (Weber et al., 2007; Fouse et al., 2008; Meissner et al., 2008; Mohn et al., 2008). In contrast to the promoters with high CG amounts (CpG-rich promoters), the methylation of promoters containing low amounts of CGs (CpG-poor promoters) seems not to preclude the binding of RNA polymerase II (Pol II). This unexpected observation led to a model where a low number or density of methylated CGs would not repress gene transcription (Weber et al., 2007; Mohn et al., 2008), probably due to the low affinity to methyl-binding proteins. However, the afore-mentioned studies were based on the quantification of immunoprecipitated methyl-cytosine- or Pol II-associated promoters in an unsynchronized cell population. Therefore, the final output reflected the average value from a mixed population of cells in different stages, that is, from cells in which the analyzed promoter might have contained bound Pol II and was transcribed, and also from cells in which the analyzed promoter might have been methylated and repressed. Given the recent discovery that cyclic DNA de/methylation is observed in synchronized cells (Kangaspeska et al., 2008; Metivier et al., 2008), it is

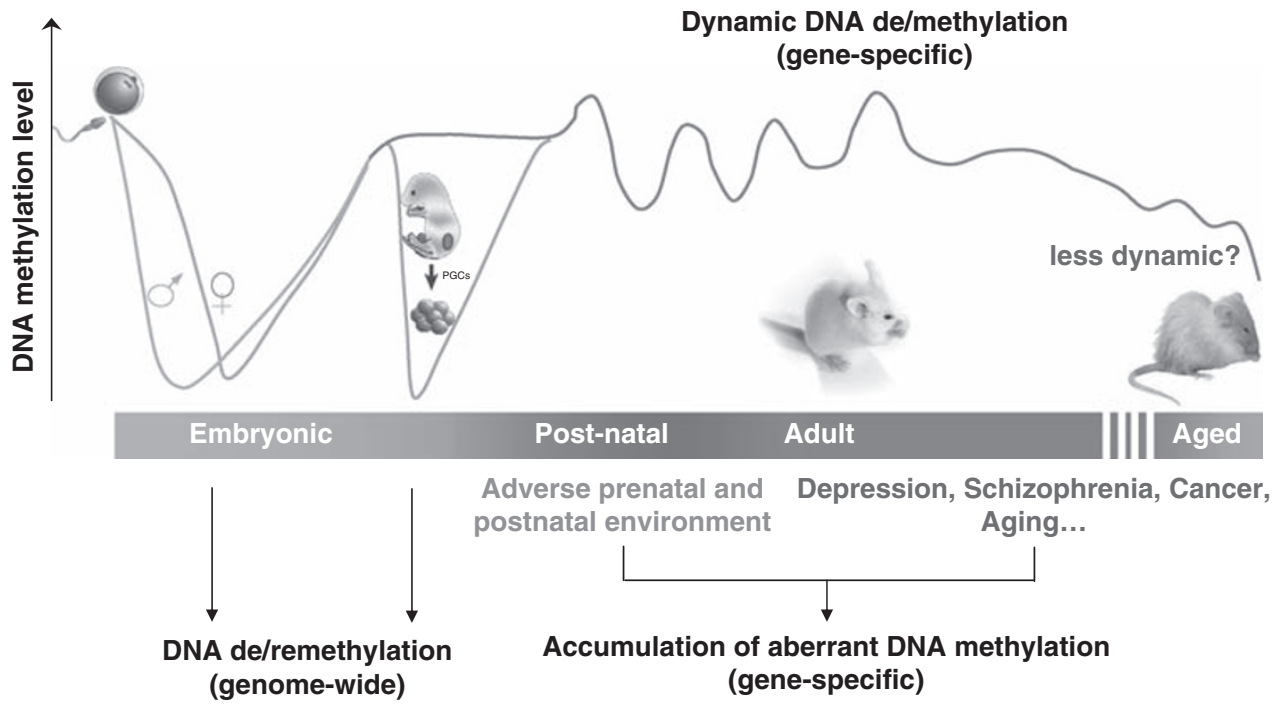

Figure 3 DNA methylation is dynamic during both embryonic and adult life. The global methylation is re-established in early embryonic life and in primordial germ cells (PGCs) (Reik, 2007). Adverse conditions during the prenatal (for example, cocaine intake of pregnant mothers) and postnatal (for example, child abuse) life seem also to alter DNA methylation postnatally and were proposed to contribute to the late onset of some complex diseases (depression, schizophrenia, cancer and so on; Szyf, 2009). Dynamic changes in gene-specific methylation have been detected in the adult brain and might be a consequence of neuronal activity (Miller and Sweatt, 2007; Lubin et al., 2008; Ma et al., 2009b). Whether the dynamics of DNA methylation changes with aging is unknown. 
possible that the CG-poor promoters might also show dynamic DNA methylation, reflecting their cycling transcription. In addition, despite the very low CG content of the analyzed estrogen-responsive gene $p S 2$, the cyclic recruitment of methyl-binding proteins observed by Metivier et al. (2008) suggested that low densities of CG methylation also may recruit methylbinding proteins.

In contrast to the CG-poor promoters, the CG-rich promoters preferentially stay unmethylated and only some become methylated during differentiation or during prolonged passaging in vitro. This led to the hypothesis that the CG-rich and CG-poor regulatory elements undergo distinct modes of epigenetic regulation (Meissner et al., 2008; Mohn and Schubeler, 2009). Previously mentioned genes that undergo dynamic changes in their promoter methylation show a similar tendency. Cyclically demethylated and methylated CGs of the estrogen-responsive $p S 2$ gene are inside the CG-poor region (Metivier et al., 2008). Transiently demethylated CGs of Fgf-1 and Bdnf from the study by Song group (Ma et al., 2009b) and CGs of Reelin and $B d n f$ genes from the study by Sweatt group (Miller and Sweatt, 2007; Lubin et al., 2008) are also situated in regions with low or moderate CG frequency, respectively. Therefore, it seems plausible that regions having lower CG frequency tend to be easily demethylated and remethylated on appropriate environmental stimuli.

Which mechanisms would enable fast CG demethylations? So far, no genuine DNA demethylase has been identified, despite numerous and often disputed candidates (Ooi and Bestor, 2008; Ma et al., 2009a). The majority of data suggest that nucleotide or base excision repair machinery could cause the removal of methylated cytosines. Some studies reported the presence of GADD45 proteins. Whether and how the stress protein, GADD45, mediates DNA demethylation is still a controversial topic (Barreto et al., 2007; Jin et al., 2008; Schmitz et al., 2009; Ma et al., 2009b). Given that active demethylation occurs on numerous neighboring CGs, as shown during electro-convulsive treatment-induced neurogenesis in adult hippocampus (Ma et al., 2009b), the removal of their methylation through the repair machinery would involve extensive damage to DNA and thus might represent a costly mechanism (Szyf, 2009). Recent evidence of deaminase activity of DNMTs suggested that DNMTs alone could cause demethylation (Metivier et al., 2008).

How would the putative DNA demethylases get recruited to the methylated CGs? Some TFs induce DNA demethylation, such as nuclear factor-kappa B (Lichtenstein et al., 1994), Egr1/NGFI-A/Zif268/ Krox-24 (Weaver et al., 2007), and the estrogen receptor that co-immunoprecipitates in the complex with DNMTs and the BER machinery (Metivier et al., 2008). Interestingly, DNA demethylation in vitro seems to follow rather than precede the early transcription and was proposed to represent a memory of actively transcribed genes (D'Alessio et al., 2007). Demethylation is observed in response to neuronal activity (Ma et al., 2009b), which implies that the activity-regulated TFs may participate in the recruitment of putative DNA demethylases. Cyclic AMP response element-binding protein is a prototypic activity-regulated TF that, on neurotrophin activation, stimulates the transcription of its responsive genes in a cyclical manner (Riccio et al., 2006).

In conclusion, it is still controversial what determines whether CG methylation stays static (irreversible) or dynamic (reversible) during the life. It seems plausible that gene regions with low/moderate CG frequency might be more prone to experience dynamic changes in their methylation, however, whether this is a consequence of their dynamic transcription remains elusive.

\section{Future Challenges}

The past decade has witnessed remarkable technical progress that has increased our knowledge of genomewide histone and DNA methylation and their dynamics during differentiation (Mikkelsen et al., 2007; Fouse et al., 2008; Meissner et al., 2008; Mohn et al., 2008; Brunner et al., 2009). Development of high-throughput (next-generation) sequencing allowed DNA methylome analysis to be more sensitive and less biased than approaches based on enzymatic digestion or methylated DNA immunoprecipitation combined with hybridization to microarrays (for review, see Lister and Ecker (2009)). As gene-case studies suggested that even single CG methylation (Mancini et al., 1999; Weaver et al., 2004, 2007; Shibuya et al., 2009) and non-CG methylation (Inoue and Oishi, 2005) could have a biological relevance, single-base analysis of genome-wide DNA methylation is of critical importance. This is now possible using bisulfite conversion combined with the next-generation sequencing (BS-Seq), which enables strand-specific and single-base resolution profiling of both CG and non-CG methylation (Cokus et al., 2008; Lister et al., 2008, 2009; Meissner et al., 2008). Nevertheless, as all of these studies assessed only the average levels of methylated DNA in a population of cells, further technical advances will hopefully allow us to shift our attention from epigenome changes in a population of cells grown in vitro toward single cells in their intact niche.

Gene-case studies also revealed the unexpected dynamicity of CG methylation in adult neurons and glia on neural circuit activation (Miller and Sweatt, 2007; Lubin et al., 2008; Yang et al., 2009; Ma et al., 2009b) and led to a partial revision of the 35-year-old idea that DNA methylation irreversibly represses gene expression (Holliday and Pugh, 1975). Many new questions about the mechanism of DNA methylation-mediated gene expression regulation in mammals have appeared: (i) what is the role of non-CG methylation in stem cells, in which it appears enriched on transcribed strands of gene bodies of highly active genes (Lister et al., 2009), and does it occur in different cell types as suggested in some studies? (Woodcock et al., 1987; Mancini et al., 1999); (ii) is CG methylation also more pronounced on the transcribed strands, as was described in ERdependent cyclic promoter methylation? (Metivier et al., 2008); (iii) do DNA methylation patterns vary among individuals? (Petronis, 2006; Illingworth et al., 2008); (iv) what is the role of $5^{\prime}$-hydroximethyl-2'-deoxycytidine, an unusual nucleotide that cannot be detected by bisulfite-based approaches, and constitutes $0.2-0.6 \%$ of all nucleotides in cerebellar Purkinje and granule neurons? (Kriaucionis and Heintz, 2009). 
Understanding the complex epigenetic regulation of neuronal activity and adult neurogenesis is integral to designing therapeutic approaches to restore neurogenesis and cognitive functions. It will also give a tremendous insight into understanding how certain environmental or pathological influences, such as stress, physical activity, depression, and epilepsy regulate adult neurogenesis. Epigenome profiling of neurogenesis in adult hippocampus is technically challenging as it requires the analysis of many distinct developmental stages. Methods such as the retroviral labeling of newborn neurons by stereotactic injections into the adult hippocampus (Jagasia et al., 2009) and laser microdissection of labeled cells (Khodosevich et al., 2007) could be used to specifically select the neural stem cells and their progeny at distinct developmental stages. Yet, the major bottleneck is the development of low/single cell-based high-throughput sequencing for epigenome profiling of stem cells and their neuronal progeny in the adult brain.

Finally, large-scale DNA methylome profiling of cells in different stages of development or cell cycle might provide us with a list of coding and/or noncoding regions that seem to remain stably methylated (such as inactive $\mathrm{X}$-chromosome and imprinted regions) and a list of genomic regions showing dynamic changes in their methylation pattern. Thus, we may finally start answering a million dollar question in epigenetics today: what distinguishes dynamic (reversible) DNA methylation from static (irreversible) DNA methylation?

\section{Conflict of interest}

The authors declare no conflict of interest.

\section{Acknowledgements}

We thank E Englberger and Dr L Berti for helpful comments on the paper. We are also grateful to Dr. W Norton and B Ebert for artwork in Figures 1 and 2. The part of the study in the Lie lab is supported by the European Young Investigator Award of the European Science Foundation (DFG 858/6-2); the Marie Curie Excellence Team Program and the Marie Curie Reintegration Program of the European Union; the Bavarian Research Network on Adult Neural Stem Cells 'FORNEUROCELL'; the Helmholtz Alliance for Mental Health in an Aging Society; the BMBF Network 'Cell Based Regenerative Medicine'; and the European Commission Coordination Action ENINET (Network of European Neuroscience Institutes; contract number LSHM-CT2005-19063).

\section{References}

Allegrucci C, Wu YZ, Thurston A, Denning CN, Priddle $\mathrm{H}$, Mummery CL et al. (2007). Restriction landmark genome scanning identifies culture-induced DNA methylation instability in the human embryonic stem cell epigenome. Hum Mol Genet 16: 1253-1268.

Ballas N, Grunseich C, Lu DD, Speh JC, Mandel G (2005). REST and its corepressors mediate plasticity of neuronal gene chromatin throughout neurogenesis. Cell 121: 645-657.

Barreto G, Schafer A, Marhold J, Stach D, Swaminathan SK, Handa V et al. (2007). Gadd45a promotes epigenetic gene activation by repair-mediated DNA demethylation. Nature 445: 671-675.

Bergami M, Santi S, Formaggio E, Cagnoli C, Verderio C, Blum $\mathrm{R}$ et al. (2008). Uptake and recycling of pro-BDNF for transmitter-induced secretion by cortical astrocytes. J Cell Biol 183: 213-221.

Bergmann A, Lane ME (2003). HIDden targets of microRNAs for growth control. Trends Biochem Sci 28: 461-463.

Bergsland M, Werme M, Malewicz M, Perlmann T, Muhr J (2006). The establishment of neuronal properties is controlled by Sox4 and Sox11. Genes Dev 20: 3475-3486.

Berninger B, Costa MR, Koch U, Schroeder T, Sutor B, Grothe B et al. (2007). Functional properties of neurons derived from in vitro reprogrammed postnatal astroglia. J Neurosci 27: 8654-8664.

Bernstein BE, Mikkelsen TS, Xie X, Kamal M, Huebert DJ, Cuff J et al. (2006). A bivalent chromatin structure marks key developmental genes in embryonic stem cells. Cell 125: 315-326.

Bertrand N, Castro DS, Guillemot F (2002). Proneural genes and the specification of neural cell types. Nat Rev Neurosci 3 : 517-530.

Bird A (2002). DNA methylation patterns and epigenetic memory. Genes Dev 16: 6-21.

Bird A (2007). Perceptions of epigenetics. Nature 447: 396-398.

Boer B, Kopp J, Mallanna S, Desler M, Chakravarthy H, Wilder PJ et al. (2007). Elevating the levels of Sox2 in embryonal carcinoma cells and embryonic stem cells inhibits the expression of Sox2:Oct-3/4 target genes. Nucleic Acids Res 35: 1773-1786.

Brunner AL, Johnson DS, Kim SW, Valouev A, Reddy TE, Neff NF et al. (2009). Distinct DNA methylation patterns characterize differentiated human embryonic stem cells and developing human fetal liver. Genome Res 19: 1044-1056.

Burgold T, Spreafico F, De Santa F, Totaro MG, Prosperini E, Natoli G et al. (2008). The histone H3 lysine 27-specific demethylase Jmjd3 is required for neural commitment. PLoS One 3: e3034.

Bylund M, Andersson E, Novitch BG, Muhr J (2003). Vertebrate neurogenesis is counteracted by Sox1-3 activity. Nat Neurosci 6: 1162-1168.

Cedar H, Bergman Y (2009). Linking DNA methylation and histone modification: patterns and paradigms. Nat Rev Genet 10: 295-304.

Chambers I, Silva J, Colby D, Nichols J, Nijmeijer B, Robertson $M$ et al. (2007). Nanog safeguards pluripotency and mediates germline development. Nature 450: 1230-1234.

Chang $\mathrm{HH}$, Hemberg $\mathrm{M}$, Barahona $\mathrm{M}$, Ingber DE, Huang $\mathrm{S}$ (2008). Transcriptome-wide noise controls lineage choice in mammalian progenitor cells. Nature 453: 544-547.

Chen WG, Chang Q, Lin Y, Meissner A, West AE, Griffith EC et al. (2003). Derepression of BDNF transcription involves calcium-dependent phosphorylation of MeCP2. Science 302: 885-889.

Cokus SJ, Feng S, Zhang X, Chen Z, Merriman B, Haudenschild CD et al. (2008). Shotgun bisulphite sequencing of the Arabidopsis genome reveals DNA methylation patterning. Nature 452: 215-219.

Colvis CM, Pollock JD, Goodman RH, Impey S, Dunn J, Mandel $\mathrm{G}$ et al. (2005). Epigenetic mechanisms and gene networks in the nervous system. J Neurosci 25: 10379-10389.

Cotman CW, Berchtold NC (2002). Exercise: a behavioral intervention to enhance brain health and plasticity. Trends Neurosci 25: 295-301.

D'Alessio AC, Weaver IC, Szyf M (2007). Acetylation-induced transcription is required for active DNA demethylation in methylation-silenced genes. Mol Cell Biol 27: 7462-7474.

Deisseroth K, Singla S, Toda H, Monje M, Palmer TD, Malenka RC (2004). Excitation-neurogenesis coupling in adult neural stem/progenitor cells. Neuron 42: 535-552. 
Drapeau E, Mayo W, Aurousseau C, Le Moal M, Piazza PV, Abrous DN (2003). Spatial memory performances of aged rats in the water maze predict levels of hippocampal neurogenesis. Proc Natl Acad Sci USA 100: 14385-14390.

Eads CA, Danenberg KD, Kawakami K, Saltz LB, Blake C, Shibata D et al. (2000). MethyLight: a high-throughput assay to measure DNA methylation. Nucleic Acids Res 28: E32.

Feng J, Chang H, Li E, Fan G (2005). Dynamic expression of de novo DNA methyltransferases Dnmt3a and Dnmt3b in the central nervous system. J Neurosci Res 79: 734-746.

Fischer A, Sananbenesi F, Wang X, Dobbin M, Tsai LH (2007). Recovery of learning and memory is associated with chromatin remodelling. Nature 447: 178-182.

Fouse SD, Shen Y, Pellegrini M, Cole S, Meissner A, Van Neste L et al. (2008). Promoter CpG methylation contributes to ES cell gene regulation in parallel with Oct4/Nanog, PcG complex, and histone H3 K4/K27 trimethylation. Cell Stem Cell 2: 160-169.

Gao Z, Ure K, Ables JL, Lagace DC, Nave KA, Goebbels S et al. (2009). Neurod1 is essential for the survival and maturation of adult-born neurons. Nat Neurosci 12: 1090-1092.

Ge S, Yang CH, Hsu KS, Ming GL, Song H (2007). A critical period for enhanced synaptic plasticity in newly generated neurons of the adult brain. Neuron 54: 559-566.

Guan JS, Haggarty SJ, Giacometti E, Dannenberg JH, Joseph N, Gao J et al. (2009). HDAC2 negatively regulates memory formation and synaptic plasticity. Nature 459: 55-60.

Guenther MG, Levine SS, Boyer LA, Jaenisch R, Young RA (2007). A chromatin landmark and transcription initiation at most promoters in human cells. Cell 130: 77-88.

Hamby ME, Coskun V, Sun YE (2008). Transcriptional regulation of neuronal differentiation: the epigenetic layer of complexity. Biochim Biophys Acta 1779: 432-437.

Hargreaves DC, Horng T, Medzhitov R (2009). Control of inducible gene expression by signal-dependent transcriptional elongation. Cell 138: 129-145.

Haslinger A, Schwarz TJ, Covic M, Chichung Lie D (2009). Expression of Sox11 in adult neurogenic niches suggests a stage-specific role in adult neurogenesis. Eur J Neurosci 29: 2103-2114.

Hayashi K, Lopes SM, Tang F, Surani MA (2008). Dynamic equilibrium and heterogeneity of mouse pluripotent stem cells with distinct functional and epigenetic states. Cell Stem Cell 3: 391-401.

Hochedlinger K, Plath K (2009). Epigenetic reprogramming and induced pluripotency. Development 136: 509-523.

Holliday R, Pugh JE (1975). DNA modification mechanisms and gene activity during development. Science 187: 226-232.

Hsieh J, Eisch AJ (2010). Epigenetics, hippocampal neurogenesis, and neuropsychiatric disorders: unraveling the genome to understand the mind. Neurobiol Dis (e-pub ahead of print 28 January 2010; PMID: 20114075).

Hsieh J, Gage FH (2005). Chromatin remodeling in neural development and plasticity. Curr Opin Cell Biol 17: 664-671.

Hublitz P, Albert M, Peters AH (2009). Mechanisms of transcriptional repression by histone lysine methylation. Int I Dev Biol 53: 335-354.

Hughes CM, Rozenblatt-Rosen O, Milne TA, Copeland TD, Levine SS, Lee JC et al. (2004). Menin associates with a trithorax family histone methyltransferase complex and with the hoxc8 locus. Mol Cell 13: 587-597.

Ikushima H, Todo T, Ino Y, Takahashi M, Miyazawa K, Miyazono K (2009). Autocrine TGF-beta signaling maintains tumorigenicity of glioma-initiating cells through Sry-related HMG-box factors. Cell Stem Cell 5: 504-514.

Illingworth R, Kerr A, Desousa D, Jorgensen H, Ellis P, Stalker J et al. (2008). A novel CpG island set identifies tissue-specific methylation at developmental gene loci. PLoS Biol 6: e22

Inoue S, Oishi M (2005). Effects of methylation of non-CpG sequence in the promoter region on the expression of human synaptotagmin XI (syt11). Gene 348: 123-134.
Jagasia R, Steib K, Englberger E, Herold S, Faus-Kessler T, Saxe $\mathrm{M}$ et al. (2009). GABA-cAMP response element-binding protein signaling regulates maturation and survival of newly generated neurons in the adult hippocampus. J Neurosci 29: 7966-7977.

Jeffares DC, Penkett CJ, Bahler J (2008). Rapidly regulated genes are intron poor. Trends Genet 24: 375-378.

Jenuwein T, Allis CD (2001). Translating the histone code. Science 293: 1074-1080.

Jepsen K, Solum D, Zhou T, McEvilly RJ, Kim HJ, Glass CK et al. (2007). SMRT-mediated repression of an H3K27 demethylase in progression from neural stem cell to neuron. Nature 450: 415-419.

Jin SG, Guo C, Pfeifer GP (2008). GADD45A does not promote DNA demethylation. PLoS Genet 4: e1000013.

Jirtle RL, Skinner MK (2007). Environmental epigenomics and disease susceptibility. Nat Rev Genet 8: 253-262.

Kandel ER (1984). Steps Toward a Molecular Grammar For Learning: Explorations Into The Nature of Memory. Wiley: New York.

Kangaspeska S, Stride B, Metivier R, Polycarpou-Schwarz M, Ibberson D, Carmouche RP et al. (2008). Transient cyclical methylation of promoter DNA. Nature 452: 112-115.

Kempermann G, Gast D, Kronenberg G, Yamaguchi M, Gage FH (2003). Early determination and long-term persistence of adult-generated new neurons in the hippocampus of mice. Development 130: 391-399.

Khodosevich K, Inta D, Seeburg PH, Monyer H (2007). Gene expression analysis of in vivo fluorescent cells. PLoS One 2: e1151.

Kim J, Chu J, Shen X, Wang J, Orkin SH (2008). An extended transcriptional network for pluripotency of embryonic stem cells. Cell 132: 1049-1061.

Kriaucionis S, Heintz N (2009). The nuclear DNA base 5-hydroxymethylcytosine is present in Purkinje neurons and the brain. Science 324: 929-930.

Kuhlbrodt K, Herbarth B, Sock E, Enderich J, HermansBorgmeyer I, Wegner M (1998). Cooperative function of POU proteins and SOX proteins in glial cells. J Biol Chem 273: 16050-16057.

Kuwabara T, Hsieh J, Muotri A, Yeo G, Warashina M, Lie DC et al. (2009). Wnt-mediated activation of NeuroD1 and retro-elements during adult neurogenesis. Nat Neurosci 12: 1097-1105.

Levenson JM, Roth TL, Lubin FD, Miller CA, Huang IC, Desai P et al. (2006). Evidence that DNA (cytosine-5) methyltransferase regulates synaptic plasticity in the hippocampus. I Biol Chem 281: 15763-15773.

Li W, Keifer J (2009). BDNF-induced synaptic delivery of AMPAR subunits is differentially dependent on NMDA receptors and requires ERK. Neurobiol Learn Mem 91: 243-249.

Lichtenstein M, Keini G, Cedar H, Bergman Y (1994). B cellspecific demethylation: a novel role for the intronic kappa chain enhancer sequence. Cell 76: 913-923.

Lie DC, Colamarino SA, Song HJ, Desire L, Mira H, Consiglio A et al. (2005). Wnt signalling regulates adult hippocampal neurogenesis. Nature 437: 1370-1375.

Lie DC, Dziewczapolski G, Willhoite AR, Kaspar BK, Shults CW, Gage FH (2002). The adult substantia nigra contains progenitor cells with neurogenic potential. J Neurosci 22: 6639-6649.

Lister R, Ecker JR (2009). Finding the fifth base: genome-wide sequencing of cytosine methylation. Genome Res 19: 959-966.

Lister R, O'Malley RC, Tonti-Filippini J, Gregory BD, Berry CC, Millar AH et al. (2008). Highly integrated single-base resolution maps of the epigenome in Arabidopsis. Cell 133: 523-536.

Lister R, Pelizzola M, Dowen RH, Hawkins RD, Hon G, Tonti-Filippini J et al. (2009). Human DNA methylomes at base resolution show widespread epigenomic differences. Nature 462: 315-322.

Liu D, Diorio J, Tannenbaum B, Caldji C, Francis D, Freedman A et al. (1997). Maternal care, hippocampal glucocorticoid 
receptors, and hypothalamic-pituitary-adrenal responses to stress. Science 277: 1659-1662.

Lubin FD, Roth TL, Sweatt JD (2008). Epigenetic regulation of $B D N F$ gene transcription in the consolidation of fear memory. J Neurosci 28: 10576-10586.

Ma DK, Guo JU, Ming GL, Song H (2009a). DNA excision repair proteins and Gadd45 as molecular players for active DNA demethylation. Cell Cycle 8: 1526-1531.

Ma DK, Jang MH, Guo JU, Kitabatake Y, Chang ML, PowAnpongkul N et al. (2009b). Neuronal activity-induced Gadd45b promotes epigenetic DNA demethylation and adult neurogenesis. Science 323: 1074-1077.

Mancini DN, Singh SM, Archer TK, Rodenhiser DI (1999). Site-specific DNA methylation in the neurofibromatosis (NF1) promoter interferes with binding of CREB and SP1 transcription factors. Oncogene 18: 4108-4119.

Martinowich K, Hattori D, Wu H, Fouse S, He F, Hu Y et al. (2003). DNA methylation-related chromatin remodeling in activity-dependent BDNF gene regulation. Science 302: 890-893.

Masui S, Nakatake Y, Toyooka Y, Shimosato D, Yagi R, Takahashi K et al. (2007). Pluripotency governed by Sox2 via regulation of Oct3/4 expression in mouse embryonic stem cells. Nat Cell Biol 9: 625-635.

McGowan PO, Sasaki A, D'Alessio AC, Dymov S, Labonte B, Szyf $M$ et al. (2009). Epigenetic regulation of the glucocorticoid receptor in human brain associates with childhood abuse. Nat Neurosci 12: 342-348.

McGowan PO, Sasaki A, Huang TC, Unterberger A, Suderman M, Ernst C et al. (2008). Promoter-wide hypermethylation of the ribosomal RNA gene promoter in the suicide brain. PLoS One 3: e2085.

Meissner A, Mikkelsen TS, Gu H, Wernig M, Hanna J, Sivachenko A et al. (2008). Genome-scale DNA methylation maps of pluripotent and differentiated cells. Nature 454: 766-770.

Metivier R, Gallais R, Tiffoche C, Le Peron C, Jurkowska RZ, Carmouche RP et al. (2008). Cyclical DNA methylation of a transcriptionally active promoter. Nature 452: 45-50.

Mikkelsen TS, Ku M, Jaffe DB, Issac B, Lieberman E, Giannoukos G et al. (2007). Genome-wide maps of chromatin state in pluripotent and lineage-committed cells. Nature 448: 553-560.

Miller CA, Sweatt JD (2007). Covalent modification of DNA regulates memory formation. Neuron 53: 857-869.

Mohn F, Schubeler D (2009). Genetics and epigenetics: stability and plasticity during cellular differentiation. Trends Genet 25: 129-136.

Mohn F, Weber M, Rebhan M, Roloff TC, Richter J, Stadler MB et al. (2008). Lineage-specific polycomb targets and de novo DNA methylation define restriction and potential of neuronal progenitors. Mol Cell 30: 755-766.

Nottke A, Colaiacovo MP, Shi Y (2009). Developmental roles of the histone lysine demethylases. Development 136: 879-889.

Novikova SI, He F, Bai J, Cutrufello NJ, Lidow MS, Undieh AS (2008). Maternal cocaine administration in mice alters DNA methylation and gene expression in hippocampal neurons of neonatal and prepubertal offspring. PLoS One 3: e1919.

Ooi SK, Bestor TH (2008). The colorful history of active DNA demethylation. Cell 133: 1145-1148.

Ordway JM, Curran T (2002). Methylation matters: modeling a manageable genome. Cell Growth Differ 13: 149-162.

Ozen I, Galichet C, Watts C, Parras C, Guillemot F, Raineteau O (2007). Proliferating neuronal progenitors in the postnatal hippocampus transiently express the proneural gene Ngn2. Eur J Neurosci 25: 2591-2603.

Penzo-Mendez AI (2010). Critical roles for SoxC transcription factors in development and cancer. Int J Biochem Cell Biol 42: $425-428$.

Petronis A (2006). Epigenetics and twins: three variations on the theme. Trends Genet 22: 347-350.
Epigenetics in adult neurogenesis

$\mathrm{M}$ Covic et al

Pleasure SJ, Collins AE, Lowenstein DH (2000). Unique expression patterns of cell fate molecules delineate sequential stages of dentate gyrus development. J Neurosci 20: 6095-6105.

Potzner MR, Griffel C, Lutjen-Drecoll E, Bosl MR, Wegner M, Sock E (2007). Prolonged Sox4 expression in oligodendrocytes interferes with normal myelination in the central nervous system. Mol Cell Biol 27: 5316-5326.

Poulter MO, Du L, Weaver IC, Palkovits M, Faludi G, Merali Z et al. (2008). GABAA receptor promoter hypermethylation in suicide brain: implications for the involvement of epigenetic processes. Biol Psychiatry 64: 645-652.

Ramirez-Carrozzi VR, Braas D, Bhatt DM, Cheng CS, Hong C, Doty KR et al. (2009). A unifying model for the selective regulation of inducible transcription by $\mathrm{CpG}$ islands and nucleosome remodeling. Cell 138: 114-128.

Rampon C, Jiang CH, Dong H, Tang YP, Lockhart DJ, Schultz PG et al. (2000). Effects of environmental enrichment on gene expression in the brain. Proc Natl Acad Sci USA 97: 12880-12884.

Ramsahoye BH, Biniszkiewicz D, Lyko F, Clark V, Bird AP, Jaenisch R (2000). Non-CpG methylation is prevalent in embryonic stem cells and may be mediated by DNA methyltransferase 3a. Proc Natl Acad Sci USA 97: 5237-5242.

Reik W (2007). Stability and flexibility of epigenetic gene regulation in mammalian development. Nature 447: 425-432.

Riccio A, Alvania RS, Lonze BE, Ramanan N, Kim T, Huang Y et al. (2006). A nitric oxide signaling pathway controls CREB-mediated gene expression in neurons. Mol Cell 21: 283-294.

Roth TL, Sweatt JD (2009). Regulation of chromatin structure in memory formation. Curr Opin Neurobiol 19: 336-342.

Roybon L, Mastracci TL, Ribeiro D, Sussel L, Brundin P, Li JY (2009). GABAergic differentiation induced by Mash1 is compromised by the bHLH proteins Neurogenin2, NeuroD1, and NeuroD2. Cereb Cortex (e-pub ahead of print 18 September 2009; PMID: 19767311).

Scharer CD, McCabe CD, Ali-Seyed M, Berger MF, Bulyk ML, Moreno CS (2009). Genome-wide promoter analysis of the SOX4 transcriptional network in prostate cancer cells. Cancer Res 69: 709-717.

Scharfman HE (2004). Functional implications of seizureinduced neurogenesis. Adv Exp Med Biol 548: 192-212.

Schmidt-Hieber C, Jonas P, Bischofberger J (2004). Enhanced synaptic plasticity in newly generated granule cells of the adult hippocampus. Nature 429: 184-187.

Schmitz KM, Schmitt N, Hoffmann-Rohrer U, Schafer A, Grummt I, Mayer C (2009). TAF12 recruits Gadd45a and the nucleotide excision repair complex to the promoter of rRNA genes leading to active DNA demethylation. Mol Cell 33: 344-353.

Shen Y, Chow J, Wang Z, Fan G (2006). Abnormal CpG island methylation occurs during in vitro differentiation of human embryonic stem cells. Hum Mol Genet 15: 2623-2635.

Shibuya K, Fukushima S, Takatsuji H (2009). RNA-directed DNA methylation induces transcriptional activation in plants. Proc Natl Acad Sci USA 106: 1660-1665.

Shihabuddin LS, Horner PJ, Ray J, Gage FH (2000). Adult spinal cord stem cells generate neurons after transplantation in the adult dentate gyrus. J Neurosci 20: 8727-8735.

Shimojo H, Ohtsuka T, Kageyama R (2008). Oscillations in notch signaling regulate maintenance of neural progenitors. Neuron 58: 52-64.

Sibbe M, Forster E, Basak O, Taylor V, Frotscher M (2009). Reelin and Notch1 cooperate in the development of the dentate gyrus. J Neurosci 29: 8578-8585.

Siegmund KD, Connor CM, Campan M, Long TI, Weisenberger DJ, Biniszkiewicz D et al. (2007). DNA methylation in the human cerebral cortex is dynamically regulated throughout the life span and involves differentiated neurons. PLoS One 2: e895. 
Sikorska M, Sandhu JK, Deb-Rinker P, Jezierski A, Leblanc J Charlebois C et al. (2008). Epigenetic modifications of SOX2 enhancers, SRR1 and SRR2, correlate with in vitro neural differentiation. J Neurosci Res 86: 1680-1693.

Song H, Stevens CF, Gage FH (2002). Astroglia induce neurogenesis from adult neural stem cells. Nature 417: 39-44.

Stock JK, Giadrossi S, Casanova M, Brookes E, Vidal M, Koseki $\mathrm{H}$ et al. (2007). Ring1-mediated ubiquitination of $\mathrm{H} 2 \mathrm{~A}$ restrains poised RNA polymerase II at bivalent genes in mouse ES cells. Nat Cell Biol 9: 1428-1435.

Suetake I, Miyazaki J, Murakami C, Takeshima H, Tajima S (2003). Distinct enzymatic properties of recombinant mouse DNA methyltransferases Dnmt3a and Dnmt3b. J Biochem 133: 737-744.

Suh H, Consiglio A, Ray J, Sawai T, D'Amour KA, Gage FH (2007). In vivo fate analysis reveals the multipotent and self-renewal capacities of Sox $2+$ neural stem cells in the adult hippocampus. Cell Stem Cell 1: 515-528.

Suzuki MM, Bird A (2008). DNA methylation landscapes: provocative insights from epigenomics. Nat Rev Genet 9: $465-476$.

Sweatt JD (2009). Experience-dependent epigenetic modifications in the central nervous system. Biol Psychiatry 65: 191-197.

Szyf M (2009). The early life environment and the epigenome. Biochim Biophys Acta 1790: 878-885.

Tong L, Shen H, Perreau VM, Balazs R, Cotman CW (2001). Effects of exercise on gene-expression profile in the rat hippocampus. Neurobiol Dis 8: 1046-1056.

Tozuka Y, Fukuda S, Namba T, Seki T, Hisatsune T (2005). GABAergic excitation promotes neuronal differentiation in adult hippocampal progenitor cells. Neuron 47: 803-815.

Tropepe V (2007). Kinship and Descent: redefining the stem cell compartment in the adult hippocampus. Cell Stem Cell 1: 481-483.

van Praag H, Shubert T, Zhao C, Gage FH (2005). Exercise enhances learning and hippocampal neurogenesis in aged mice. J Neurosci 25: 8680-8685.
Veldic M, Guidotti A, Maloku E, Davis JM, Costa E (2005). In psychosis, cortical interneurons overexpress DNAmethyltransferase 1. Proc Natl Acad Sci USA 102: 2152-2157.

Waddington CH (1940). Organisers and Genes. Cambridge University Press: Cambridge.

Walsh CP, Bestor TH (1999). Cytosine methylation and mammalian development. Genes Dev 13: 26-34.

Weaver IC, D'Alessio AC, Brown SE, Hellstrom IC, Dymov S, Sharma $S$ et al. (2007). The transcription factor nerve growth factor-inducible protein a mediates epigenetic programming: altering epigenetic marks by immediate-early genes. J Neurosci 27: 1756-1768.

Weaver IC, Diorio J, Seckl JR, Szyf M, Meaney MJ (2004). Early environmental regulation of hippocampal glucocorticoid receptor gene expression: characterization of intracellular mediators and potential genomic target sites. Ann NY Acad Sci 1024: 182-212.

Weber M, Hellmann I, Stadler MB, Ramos L, Paabo S, Rebhan M et al. (2007). Distribution, silencing potential and evolutionary impact of promoter DNA methylation in the human genome. Nat Genet 39: 457-466.

Wolffe AP, Matzke MA (1999). Epigenetics: regulation through repression. Science 286: 481-486.

Woodcock DM, Crowther PJ, Diver WP (1987). The majority of methylated deoxycytidines in human DNA are not in the CpG dinucleotide. Biochem Biophys Res Commun 145: 888-894.

Yang Y, Gozen O, Vidensky S, Robinson MB, Rothstein JD (2009). Epigenetic regulation of neuron-dependent induction of astroglial synaptic protein GLT1. Glia.

Zhao C, Deng W, Gage FH (2008). Mechanisms and functional implications of adult neurogenesis. Cell 132: 645-660.

Zhao S, Chai X, Frotscher M (2007a). Balance between neurogenesis and gliogenesis in the adult hippocampus: role for reelin. Dev Neurosci 29: 84-90.

Zhao XD, Han X, Chew JL, Liu J, Chiu KP, Choo A et al. (2007b). Whole-genome mapping of histone H3 Lys4 and 27 trimethylations reveals distinct genomic compartments in human embryonic stem cells. Cell Stem Cell 1: 286-298. 